\title{
Mechanical properties of a carbonate sand from a dredged hydraulic fill
}

\author{
D. GIRETTI*, V. FIORAVANTE $\dagger$, K. BEEN $\ddagger$ and S. DICKENSON§
}

\begin{abstract}
This paper focuses on the properties of a crushable, uncemented, carbonate sand, retrieved from an artificial island to be used for petroleum production offshore of the United Arab Emirates. The sand was dredged from an offshore borrow area, placed hydraulically within engineered bunds to create the island and densified by vibroflotation. The results of a comprehensive laboratory testing programme are summarised in this paper, providing a set of mechanical properties for carbonate sand. The laboratory programme included static, cyclic and dynamic tests, the results of which are interpreted in a critical state soil mechanics framework, including stress dilatancy. The results of this testing programme contribute to on-going research on the behaviour of carbonate sands under static and cyclic loading conditions. The results are also compared with selected data for other carbonate and siliceous sands, and highlight the behaviour of crushable, carbonate sands used as hydraulic fills.
\end{abstract}

KEYWORDS: calcareous soils; laboratory tests; sands

\section{INTRODUCTION}

The focus of this paper is on the properties of a carbonate sand with relatively crushable particles. The tested soil is not a typical in situ, aged, carbonate sand in which cementing is a key component of behaviour. The sand was dredged from the Persian Gulf offshore of the United Arab Emirates (UAE) for use as hydraulic fill to construct petroleum production islands. The resulting material has little or no bonding or cementation, and the grains are highly crushable. The crushing of grains during loading results in a soil behaviour that has been commonly interpreted as similar to "compressible sand', although there is no widely adopted definition of compressibility as applied to various types of sand. The term 'compressibility' is often defined as related to modulus; however, the loading conditions and characterisation of the strains (i.e. elastic, plastic or both) are undefined. Within the context of cone penetration test (CPT) interpretation in sands, compressibility is important, but it is seldom correlated with laboratory data due to the inherent difficulty in sampling sands. Compressibility is therefore routinely estimated based on knowledge of index properties and local experience with similar soils.

In light of peculiar aspects of the stress-strain behaviour of the soil investigated on this project, the primary objective of this paper is to provide a comprehensive data set on mechanical properties of a crushable, carbonate sand. Thorough treatment of the mechanical properties of these sands is limited in the technical literature; however, useful background and data have been presented by the following investigators: Fookes (1988), Golightly (1988), Golightly \& Hyde (1988), Coop (1990), Coop \& Atkinson (1993), Coop \& Cuccovillo (1998), Coop et al. (2004), Coop \& Airey (2003), Fioravante et al. (1994a, 1994b, 1998, 2013), Qadimi \& Coop (2007), Al-Douri \& Poulos (1991), Hyodo et al. (1998), Mao \& Fahey (2003), Porcino et al. (2008) and

Manuscript received 25 November 2016; revised manuscript accepted 4 July 2017.

Discussion on this paper is welcomed by the editor.

* ISMGEO srl, Seriate, Bergamo, Italy (Orcid:0000-0003-4145-1388).

$\dagger$ University of Ferrara, Ferrara, Italy.

t Golder Associates Ltd, Halifax, NS, Canada.

$\S$ New Albion Geotechnical Inc., Reno, NV, USA.
Van Impe et al. (2015). Publications such as ISO 19901-4 (ISO, 2016) are applicable to siliceous sands and provide warnings to the effect that 'carbonate sands are different and need special expertise'. In addition, the Hydraulic fill manual for dredging and reclamation works (van't Hoff \& van der Kolff, 2012) provides guidance based largely on the above references, and particularly notes that carbonate sands can provide satisfactory performance as hydraulic fills, provided the material behaviour is adequately addressed and the differences relative to silica sands are recognised. The data presented herein have been gathered as part of a major offshore engineering project and the scope of the testing programme provides a useful example of an integrated programme of laboratory testing, leading to the mechanical characterisation of a specific, and rather unique, soil. The potential variability in the behaviour of various carbonate sands is addressed, demonstrating the uncertainties associated with assigning properties for crushable, carbonate sands on the basis of data from other regions, soil types and depositional environments.

A premise behind this paper is that undisturbed sampling and testing of offshore, hydraulically placed sand and silt fill materials is impractical for most projects due to the considerable added time, expense and associated technical issues. In light of this limitation, it is most common to work with disturbed or reconstituted materials, which is deemed useful as a starting point for the characterisation of hydraulic fills. The paper draws together the results of testing in a critical state soil mechanics (CSSM) framework (Schofield \& Wroth, 1968) as it captures volume change during shearing of soils and quantifies compressibility in defined terms. The results are compared with selected data for other carbonate and siliceous sands, thereby highlighting the range of material properties for carbonate sands and providing practical information for designers and constructors of fills with the same, or similar, crushable sands. The database for carbonate sands presented herein supplements existing data in the technical literature and provides additional support for initial characterisation of the range of likely mechanical properties and soil behaviour for hydraulically placed fill of similar carbonate sands.

\section{BEHAVIOUR OF CARBONATE SANDS}

Carbonate soils are calcareous sediments in which calcium carbonate (aragonite or calcite) is predominant. They may 
have organic (biogenic soils, originated by the deposition of skeletal residue of marine organisms) or chemical origins (oolitic soils, derived from the precipitation of aragonite around a nucleation site in carbonate-rich water). They are deposited in a wide range of geological environments and their grain size distribution may range from sand sizes to muds (clay sizes).

Biogenic carbonate sands are generally composed of elongated particles with angular shape and intra-particle voids, which, at the macro-scale, results in a loose structure with higher void ratio in general than that of silica sands. When compressed or sheared, the particles may crush or break at the asperities. The high void ratio and crushability of particles both contribute to high compressibility, as indicated by the slope of the normal compression and critical state lines (Coop, 1990; Coop \& Airey, 2003). Breakage of soil grains results in irreversible plastic strains and relatively low slope of the unloading and re-loading lines. Also, the creep rate and the associated strain rate effects can be large.

Characterisation of the cyclic resistance and nature of excess pore pressure generation leading to liquefaction of carbonate sands is a topic of active research, with limited coverage in the technical literature. Practice-oriented procedures for evaluating the triggering of liquefaction in sands (e.g. Robertson, 2009; Boulanger \& Idriss, 2014) are based on in situ penetration tests involving the standard penetration test (SPT) and CPT, therefore may introduce uncertainties associated with the effects of crushing of carbonate grains compared to harder grains found in siliceous sands, which are the basis for most of the research, data and engineering correlations associated with penetration testing. In effect, the tip resistance, $q_{\mathrm{c}}$, or blow count, $N$ value in a carbonate sand represents a higher relative density than the same $q_{\mathrm{c}}$ or $N$ value in a silica sand. Marioka \& Nicholson (2000) report the results of calibration chamber penetration tests on a non-cemented calcareous sand and a silica sand, which demonstrated that the tip resistance of the latter is 1.5 to 2 times greater than that of the calcareous sand at similar relative densities, consistent with the findings by Almeida et al. (1991). This is attributed to a higher compressibility as a result of crushing of the carbonate sand grains. It is noted that the range of compressibility in various siliceous sands is considered in many analysis methods.

A second consideration is that the cyclic strength (measured in the laboratory by cyclic simple shear or triaxial tests) appears to be higher in carbonate than in siliceous sands, at the same relative density (Hyodo et al., 1998; Marioka \& Nicholson, 2000; Brandes, 2011; Sandoval et al., 2011). This may be due to crushing of the particles. The energy transmitted to the grains by cyclic loading is partially dissipated by crushing and as a consequence a higher resistance to liquefaction is generally experienced. Marioka \& Nicholson (2000) and Sandoval et al. (2011) also observed an important difference in pore pressure generation between carbonate and silica sand - that is, larger fluctuations in the excess pore pressure (or pore pressure relaxation) suggesting greater resistance against particle rearrangement and fewer particle movements towards a different grain packing in the calcareous soil structure. These factors suggest that for the same penetration resistance carbonate sands would have a higher liquefaction resistance compared to silica sands. Substantially more cyclic data are required to support this general hypothesis as the limited reported data are inconclusive. For example, data from a site in Guam suggest that there may be little difference (LaVielle, 2008) in coralline, carbonate sands.

The mechanical behaviour of carbonate sand is often related to that of silica sands. The behaviours of both have been found to be dependent on the state of the sand (specific volume and mean effective pressure); however, significant differences are observed in the laboratory and in situ testing. Carbonate sands have higher values of the shearing resistance angle both at peak and at critical state relative to that of more typical silica sands, possibly due to the elongated shape particles and high grain surface roughness, which could contribute to interlocking (Al-Douri \& Poulos, 1991; Coop \& Airey, 2003). The strains required to mobilise peak and critical state resistance are generally higher than for silica sand (Al-Douri \& Poulos, 1991). These differences highlight the need for enhanced characterisation of the mechanical behaviour of carbonate sands by means of integrated in situ and laboratory testing programmes that could be used to develop robust and practical empirical correlations developed specifically for crushable, carbonate sands.

\section{INTRINSIC PROPERTIES OF CARBONATE SAND M1}

The M1 carbonate sand was obtained from an artificial island to be used for petroleum production offshore from the UAE. The sand was dredged from an offshore borrow area and hydraulically placed within engineered containment bunds. After placement, a comprehensive vibroflotation programme had been carried out to densify the sand, in order to provide satisfactory foundation bearing capacity, to limit static settlement under load, and increase the resistance to liquefaction.

The material 'as dredged' from the borrow source was a lightly cemented material which included large (gravel- and cobble-sized) particles as well as sand-sized material. By the time the material had passed through dredging pumps, been placed in the island and densified, it was almost entirely sand-sized and had about $91 \%$ sand-sized particles, fines content of $4 \cdot 8 \%$ and gravel-like content of $4 \cdot 4 \%$.

M1 sand is a biogenic carbonate sand with a carbonate content higher than $97 \%$. The primary mineralogical components are aragonite $\left(\mathrm{CaCO}_{3}\right.$, orthorhombic polymorph $\sim 72-76 \%$; calcite $\left(\mathrm{CaCO}_{3}\right.$, trigonal polymorph) $\sim 10-12 \%$ and magnesium-calcite $\left(\mathrm{Mg}_{0 \cdot 1} \mathrm{Ca}_{0 \cdot 9} \mathrm{CO}_{3}\right)$ $\sim 11-13 \%$. The sand is composed of fragments of shells of bivalve molluscs, vermetid gastropods, foraminifera, bryozoans, echinoids, sponge spicules, small amounts of coral fragments as well as clasts of micritic limestones and sparry calcite (Fig. 1). The grains are characterised by micro-porosity, not only in the rare coral fragments, in foraminifera and other bioclasts, but also in the micritic

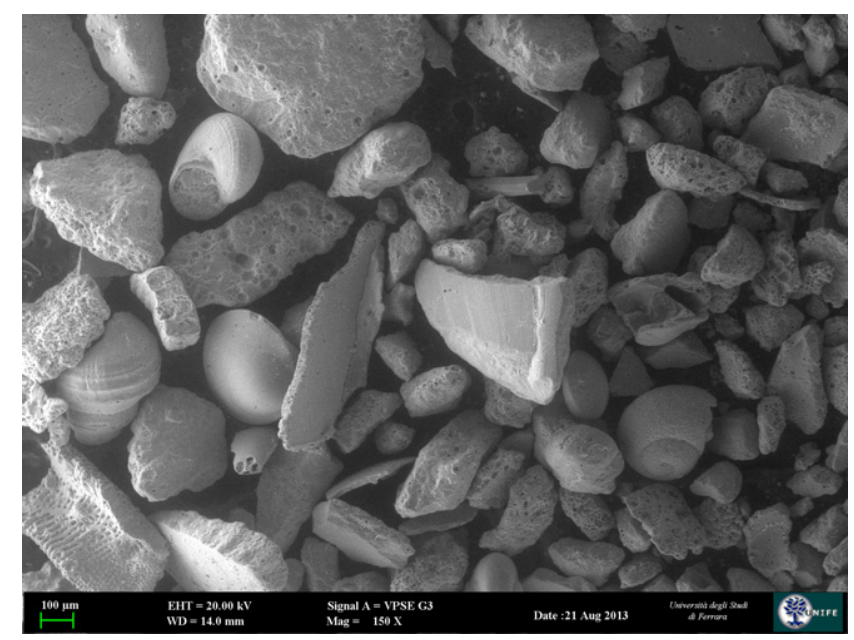

Fig. 1. Photograph of M1 carbonate sand as sampled in hydraulic fill island after placement and densification 


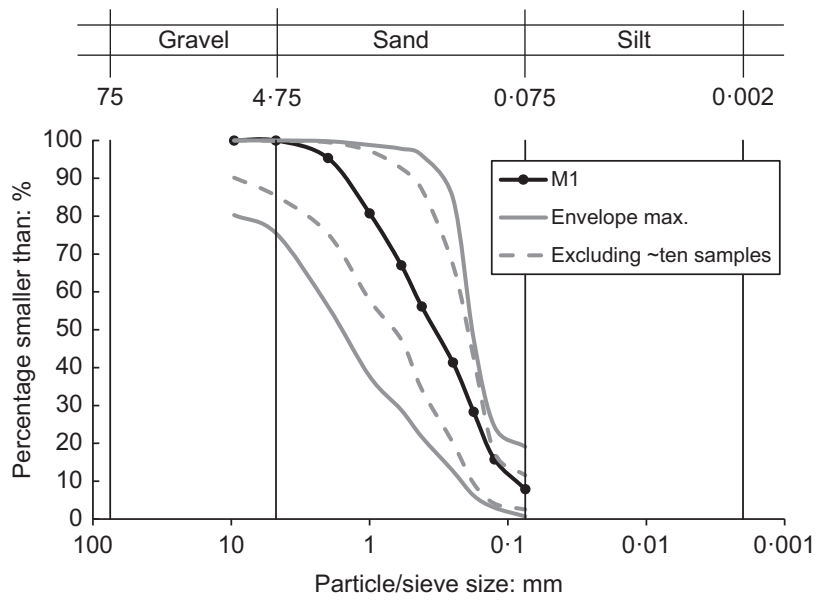

Fig. 2. Grain size distribution of sampled sands and blended samples used for laboratory testing

limestone grains. On the clast surfaces, fine borings due to action of endolithic algae are present in some cases.

The particle size distribution envelope obtained on about 400 samples from the island fill is shown in Fig. 2. Eliminating the ten outlier samples from the 400 results in a narrower range of grain sizes (Fig. 2). The sand described in this paper was obtained by blending a number of samples into a bulk sample (called M1), which provided a reasonable representation of the range of grain sizes in the field. The grain size parameters for M1 are: $D_{10}=0.085$, $D_{50}=0.339, D_{60}=0.474, U_{\mathrm{c}}=5.6$ and fines content $7.9 \%$. Particles larger than $4.75 \mathrm{~mm}$ (gravel sizes) were removed in the M1 bulk sample. The specific gravity is $G_{\mathrm{s}}=2 \cdot 812$.

\section{COMPRESSIBILTY OF M1 CARBONATE SAND}

Compressibility of saturated M1 sand was investigated in four different tests: an isotropic triaxial consolidation test, a one-dimensional oedometer compression test $(25 \cdot 4 \mathrm{~mm}$ dia. specimen) and two large one-dimensional oedometer tests (400 $\mathrm{mm}$ dia. specimen prepared by dry pluvial deposition). Results of these tests are shown in Fig. 3. The results of similar tests on various carbonate sands are provided in Fig. 3 to demonstrate the variability inherent in compressibility for these soils, highlighting the need for thorough characterisation of the soils prior to assigning material properties for analysis.

In Fig. 3(a) the isotropic consolidation test is compared with data from Coop \& Airey (2003). M1 sand starts at a lower void ratio due to the target density at the beginning of the compression testing; however, once the stress approaches $10 \mathrm{MPa}$ the void ratio is comparable to the other sands reported by Coop \& Airey (2003) and the slope of the compression curve is trending to a similar value.

Figure 3(b) shows the results of small and large oedometer tests compared to data from Almeida et al. (1991) and Pestana \& Whittle (1995). The maximum applied stress for the large oedometer sample was limited by the testing apparatus. The M1 sand compression and rebound curves measured by the small oedometer compare well with the published data for the Quiou sand. Results of dry and saturated large oedometer tests are similar.

\section{CRITICAL STATE LINE AND STRESS DILATANCY IN M1 CARBONATE SAND}

A total of 16 drained and 21 undrained triaxial tests were carried out on M1 sand. The results of all the tests considered



(a)

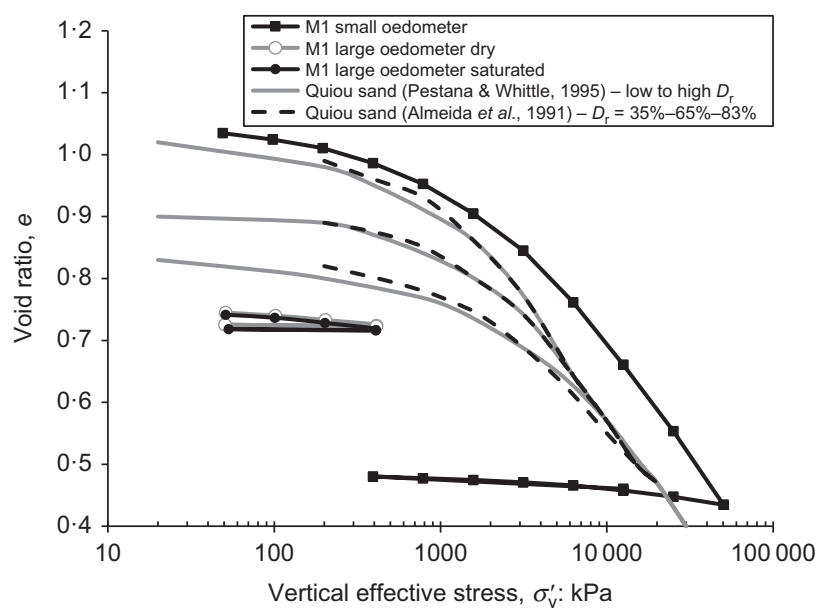

(b)

Fig. 3. Comparison of M1 sand compressibility with other carbonate sands: (a) isotropic consolidation, data from Coop \& Airey (2003); (b) one-dimensional consolidation

to define the critical state line (CSL) and the stress dilatancy of M1 sand are provided as on-line supplementary material. The specimens were prepared by dry pluvial deposition and generally consolidated isotropically, although 15 tests were performed with anisotropic consolidation. Figs 4(a)-4(c) show the results of four undrained and four drained triaxial tests. The state paths of all the drained and undrained tests that were considered to reach the critical state are shown in the $e-\log p^{\prime}$ plane (Fig. 5).

The undrained tests on Figs 4(a) and 4(b) show positive pore water pressures and an initial yield with strains of a few percent before dilation is initiated, resulting in a reduction in the pore pressures and increase in the deviator stress. The tests all approach the critical state at large strains. The state diagram (Fig. 5) shows these tests, as well as the CSL fitted to the whole data set, which includes eight undrained tests not shown on Fig. 4 and four drained tests that were considered to reach the critical state. Open circles represent the start of undrained shearing conditions; solid diamond symbols are the end of undrained tests or critical state conditions. The state paths themselves are horizontal lines between these symbols, since the tests are undrained and therefore at a constant void ratio.

As to the behaviour of M1 sand under drained conditions, the right-hand side of Fig. 4(b) shows compression (positive volumetric strains) initially, followed by dilation (volumetric strain decreasing) occurring at strains that are larger than typically seen in silica sands. This behaviour is also reflected 

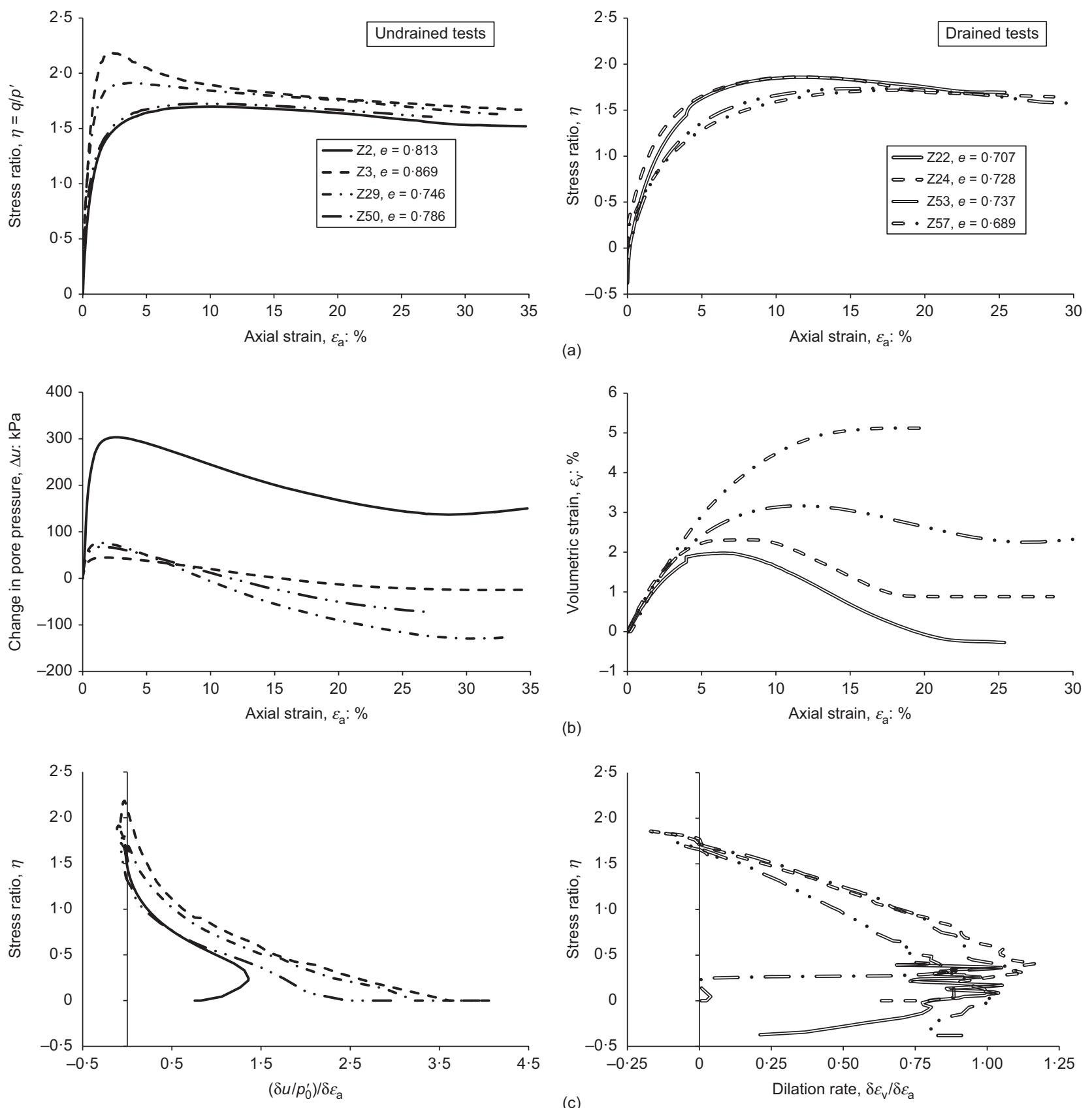

Fig. 4. Examples of triaxial tests on M1 sand specimens. Selected undrained tests are given in the left-hand column and selected drained tests in the right-hand column: (a) stress-strain behaviour; (b) excess pore pressure for undrained tests, volumetric strains for drained tests plotted against axial strain; (c) stress ratio plotted against the normalised pore pressure for undrained tests and the dilation rate for drained tests

in the stress ratio $\eta=q / p^{\prime}$, Fig. 4(a), with a relatively soft initial response and large strains before the peak ratio is reached, and is attributed to compressibility associated with crushing. The drained state paths on the state diagram (Fig. 5) experience a change in void ratio and have a hooked shape for tests starting below the CSL: for example, test Z53 (initial void ratio, $e=0 \cdot 737$, consolidated to $400 \mathrm{kPa}$ ), signifying dilation with a bit of post-peak softening leading to a reduction in mean stress. Test Z57 (initial void ratio $e=0 \cdot 718$, consolidated to relatively high stress $800 \mathrm{kPa}$ ) starts above the CSL, so no dilation is experienced and the state path is not hooked. The selected tests get close to the critical state at large strains, as shown on the state diagram, with the critical state points represented as open diamond symbols.

The lower right diagram on Fig. 4(c) shows the stress dilatancy for the drained tests, in terms of how the stress ratio and dilation rate develop during each test. The end point of a test, if at the critical state, should occur at zero dilation rate (by definition of the critical state) and a stress ratio $\eta=M$. Negative dilation rates are associated with peak strengths higher than $M$, indicating the effects of stress dilatancy on specimens that start below the CSL. Specimens above the CSL do not extend into negative dilation rate but terminate at close to zero, that is, the CSL. An analogous plot is shown on the lower left of Fig. 4(c) for undrained tests: the stress ratio is represented against the ratio of the normalised pore pressure to axial strain $\left(\delta u / p_{0}^{\prime}\right) / \delta \varepsilon_{\mathrm{a}}$ ( $p_{0}^{\prime}$ is the consolidation pressure). At the end of the undrained tests the stress ratio is $M$ and the pore pressure rate is zero.

The state diagram on Fig. 5 shows the best-fit CSL for M1 sand in $e-\log p^{\prime}$ space. In the stress and void ratio range investigated, the critical states in the $e-\log p^{\prime}$ space are almost aligned; that is, they fall in the straight part of the CSL. At lower stress and higher void ratio the CSL should 


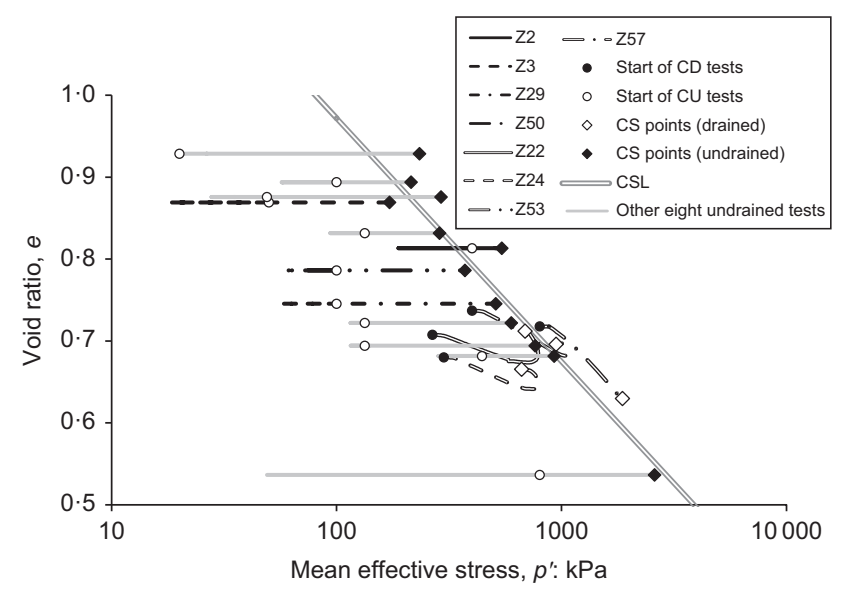

Fig. 5. Interpreted CSL for M1 sand on $e-\log p^{\prime}$ state diagram (CD, consolidated drained; $\mathrm{CU}$, consolidated undrained)

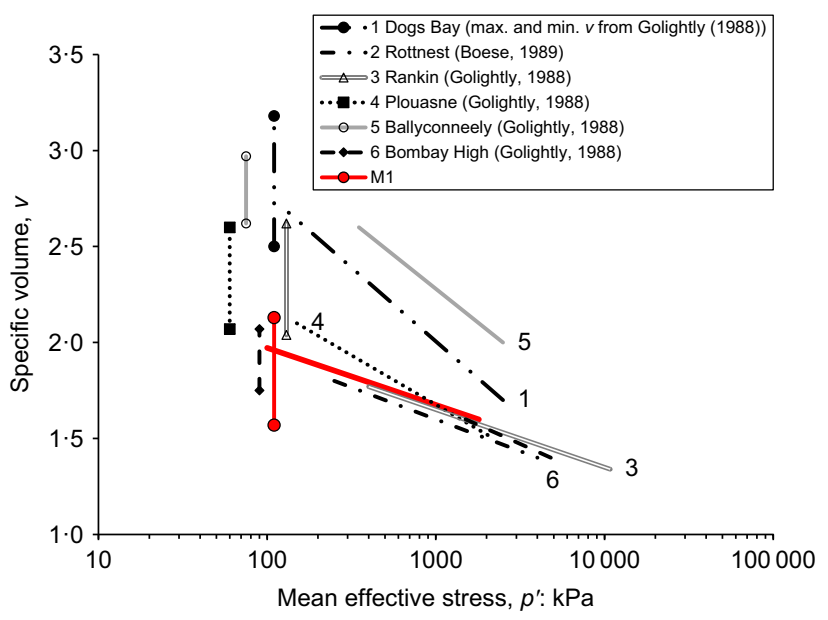

Fig. 6. Comparison of M1 CSL with other carbonate sands (data from Coop \& Airey (2003), based on Golightly (1988))

probably curve towards the horizontal (Verdugo \& Ishihara, 1996), but in the stress range of $100-2000 \mathrm{kPa}$, the assumption of a linear CSL was considered acceptable. The equation adopted to define the CSL is the following:

$$
e_{\mathrm{cs}}=\Gamma_{1}-\lambda_{10} \log p^{\prime}
$$

where $e_{\mathrm{cs}}$ is the critical state void ratio, $\Gamma_{1}$ is the void ratio defined at $p^{\prime}=1 \mathrm{kPa}$ and $\lambda_{10}$ is the slope of the CSL using logarithms to base 10 . For M1 sand, $\Gamma_{1}=1.566$ and $\lambda_{10}=0.296\left(\lambda_{\mathrm{e}}=0.129\right)$. Deviation from this linear approximation could be expected at both low stresses (as there is a maximum possible void ratio) and at high stresses (due to crushing of particles).

A comparison of the CSL for M1 sand with other carbonate sands is shown on Fig. 6, as well as values of maximum and minimum specific volume for each sand. M1 sand CSL is comparable to several of the other sands that lie in the lower specific volume range of $1 \cdot 5-2 \cdot 0$ (void ratio $0 \cdot 5-1 \cdot 0)$. Compared to silica sands, M1 sand has higher $\Gamma_{1}$ and $\lambda_{10}$ (and $M$ - see below), consistent with expectations based on the nature and behaviour of carbonate sands, as previously addressed.

Stress-dilatancy refers to the volumetric changes in sand as a result of mobilised shear strains and applied stresses. It is an intrinsic part of soil behaviour, addressed within the CSSM framework of this paper. Fig. 7 shows the peak stress ratio achieved in drained tests on M1 sand against the maximum

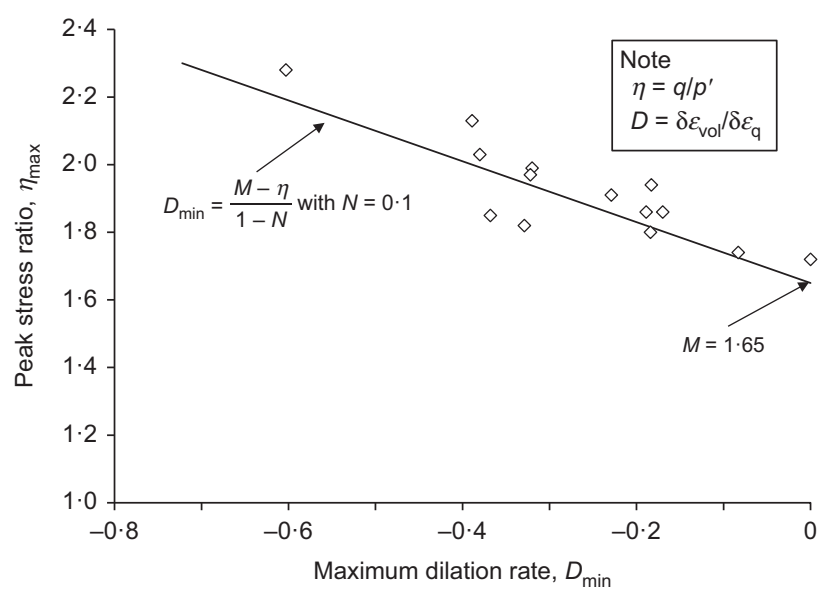

Fig. 7. Stress dilatancy of M1 sand in terms of stress invariants $\eta_{\max }$ plotted against $D_{\text {min }}$

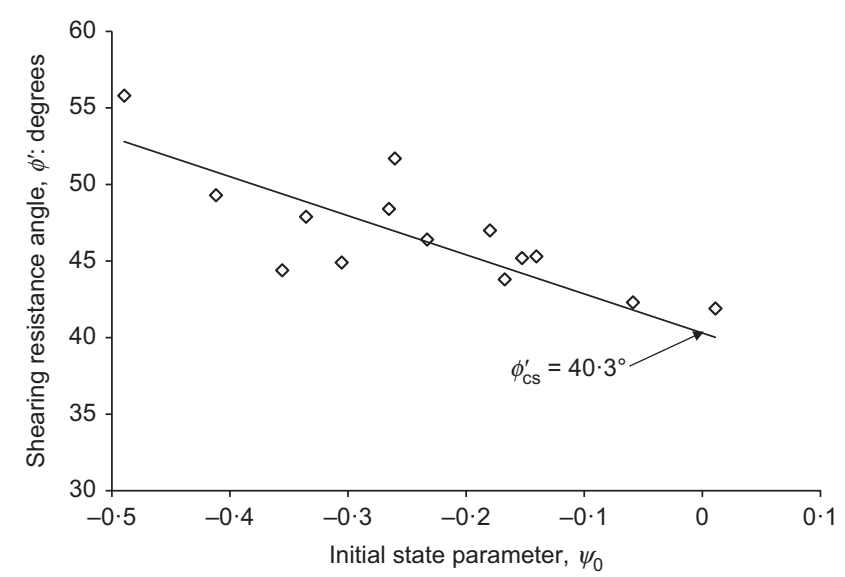

Fig. 8. Shear resistance angle $\phi^{\prime}$ plotted against state parameter $\psi_{0}$ for M1 sand

dilation rate in the same test. $D$ is defined in stress invariant terms consistent with stress ratio: $\eta=q / p^{\prime}$ and $D_{\min }=\dot{\varepsilon}_{\mathrm{v}} / \dot{\varepsilon}_{\mathrm{q}}$. Total strains have been used to simplify the calculations, because the elastic components of strain are negligible compared to plastic strains at peak conditions and as the critical state is approached. The trendline sketched in Fig. 7 gives the value of $M=1.65$ at the intercept where dilation rate is zero, that is, the critical state. This value is consistent with the value of $M$ that would be inferred from zero rates of pore pressure (undrained tests) and dilatancy (drained tests) on Fig. 4(c).

Application of the CSSM framework for sands requires definition of the state parameter $\psi$ (Been \& Jefferies, 1985), which is the distance, in terms of void ratio, that the state of a soil is from the CSL at the same mean effective stress. As the state parameter is defined in relation to the CSL, it is a measure of how much dilation needs to occur during shearing before the CSL is reached. Been \& Jefferies (1985) related shear resistance angle to initial state parameter $\psi_{0}$ to show the usefulness of the framework and as a basis for subsequent CSSM models including stress dilatancy. The relationship for M1 sand is shown in Fig. 8. The state parameter framework is applicable to M1 sand as anticipated.

The parameters describing stress dilatancy are $M, N$ and $\chi$. $M$ is the critical state stress ratio $(M=1 \cdot 65) ; N$ is a volumetric coupling parameter obtained from the slope of the $\eta_{\max }$ plotted against $D_{\min }$ line (Nova, 1982) as shown on Fig. 7 


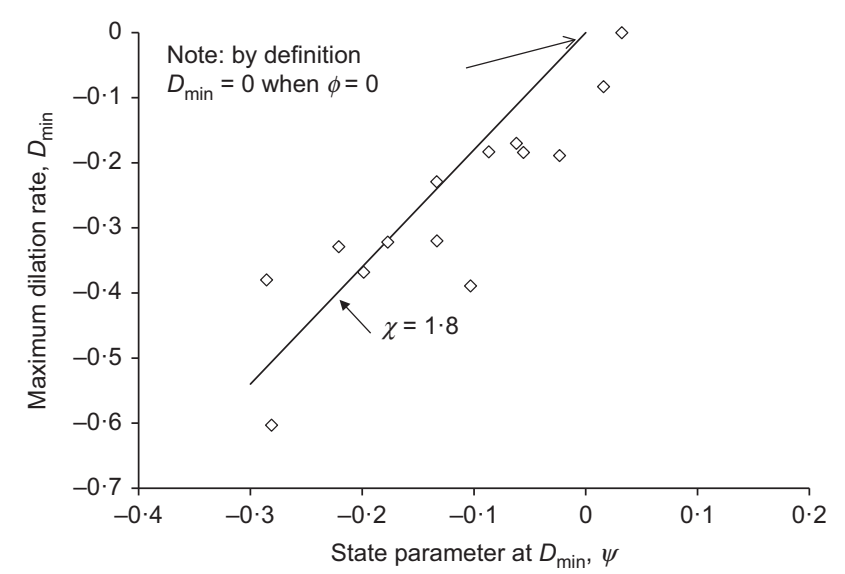

Fig. 9. Dilatancy scaling for M1 sand $\left(D_{\min }\right.$ plotted against $\psi$ at $\left.D_{\min }\right)$

$(N=0 \cdot 1)$. The dilatancy rate scaling parameter $\chi$ distinguishes materials that show different dilatancy at the same value of state parameter. It is the slope of the line obtained when $D_{\min }$ is plotted against $\psi$ at which $D_{\min }$ occurs; that is, the current value of state parameter as opposed to the initial value $\psi_{0}$. Fig. 9 shows the derivation of $\chi=1 \cdot 8$. This dilatancy rate scaling post-dates the initial work of Been \& Jefferies (1985), when it was assumed that the relationship between $D_{\min }$ and $\psi$ was unique $(\chi \sim 3.5)$ based on a range of testing available at the time. However, as the state parameter has been extended to a broader range of materials, including mine tailings and pure silts, there seems to be a different sensitivity to the effect of volumetric strain depending on the grain size distribution, particle shapes and potentially other key factors which have not yet been identified. In general, well-graded soils have less free void space than some silts and poorly graded soils, and so there are subtle differences in dilatancy scaling with state parameter captured within $\chi$ (Jefferies \& Been, 2015). Although the use of $\chi$ as a soil index is novel and further research is needed, it is interesting to note that M1 sand has a low value compared to silica sands, potentially indicating that sands with crushable grains show weaker dilatancy than sands with hard grains.

\section{DYNAMIC PROPERTIES OF M1 CARBONATE SAND}

A series of shear and compression wave velocity measurements using bender and compression elements was performed on triaxial specimens of dry M1 sand to determine the variation of the small-strain shear and constrained stiffness as a function of void ratio and vertical and horizontal effective stresses. Fig. 10 shows the measured $V_{\mathrm{s}}$ and $V_{\mathrm{p}}$ as a function of the vertical applied stress $\sigma_{\mathrm{v}}^{\prime}$ for M1 sand. At the same applied vertical stress and void ratio, the shear wave velocity increases with horizontal stress, indicated by the stress ratio, $K\left(K=\sigma_{\mathrm{h}}^{\prime} / \sigma_{\mathrm{v}}^{\prime}\right)$, while the compression wave velocity is almost unaffected by the horizontal stress. The measurements have been analysed to derive a correlation between shear and compression moduli, void ratio and stresses, in the form proposed by Fioravante (2000) and Fioravante et al. (2013). The small-strain shear and compression moduli $G_{\max }$ and $M_{\max }$ are related to the shear and compression wave velocities, respectively, through the theory of wave propagation in elastic media as

$$
\begin{aligned}
& G_{\max }=\rho V_{\mathrm{S}}^{2} \quad\left(\mathrm{FL}^{-2}\right) \\
& M_{\max }=\rho V_{\mathrm{P}}^{2} \quad\left(\mathrm{FL}^{-2}\right)
\end{aligned}
$$

where $\rho=$ soil mass density.

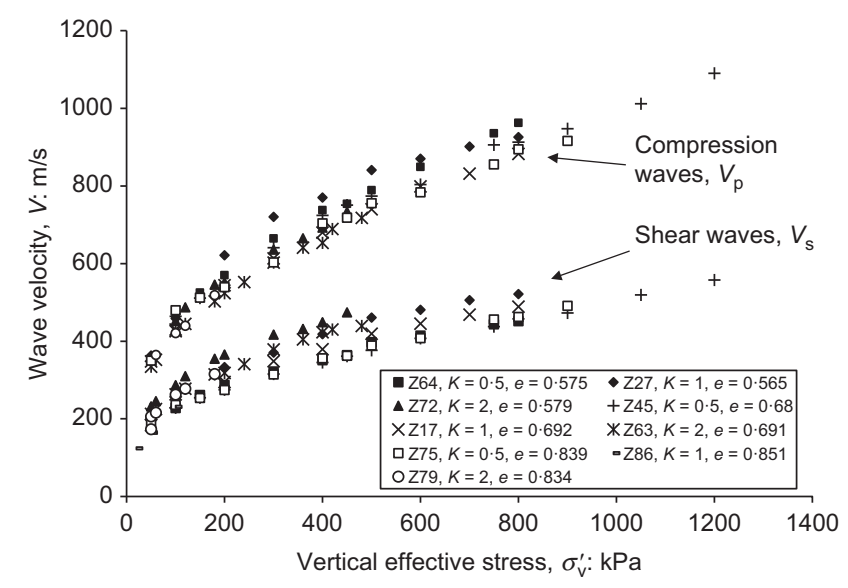

Fig. 10. Trends in compression and shear wave velocity in dry M1 sand as functions of void ratio and effective stress

The relation between shear modulus and soil state (void ratio and stresses) is

$$
G_{\max }=C_{\mathrm{G}} e^{d}\left(\frac{\sigma_{\mathrm{v}}}{p_{\text {ref }}}\right)^{n_{\mathrm{v}}}\left(\frac{\sigma_{\mathrm{h}}}{p_{\text {ref }}}\right)^{n_{\mathrm{h}}}\left(\mathrm{FL}^{-2}\right)
$$

where $C_{\mathrm{G}}=65 \cdot 3 \mathrm{MPa}$ is the material constant corresponding to the value of $G_{\max }$ at the reference conditions; $d=-1$; $n_{\mathrm{v}}=0 \cdot 378 ; n_{\mathrm{h}}=0 \cdot 306$.

In Table 1 the values of these calibration coefficients are compared to those found by Fioravante et al. (1998), Fioravante et al. (2013) and Van Impe et al. (2015) for Quiou, Kenya and three carbonate sands (S1, BAE and BAW sands, used for an offshore land reclamation in the Persian Gulf), respectively. For comparison, the values calibrated for Ticino silica sand by Fioravante (2000) are also reported.

The relation between constrained modulus and soil state (void ratio and stresses) is

$$
M_{\max }=C_{\mathrm{M}} e^{d}\left(\frac{\sigma_{\mathrm{v}}}{p_{\text {ref }}}\right)^{m_{\mathrm{v}}}\left(\frac{\sigma_{\mathrm{h}}}{p_{\text {ref }}}\right)^{m_{\mathrm{h}}}\left(\mathrm{FL}^{-2}\right)
$$

where $C_{\mathrm{M}}=213 \mathrm{MPa}$ is the material constant corresponding to the value of $M_{\max }$ at the reference conditions; $d=-1(-)$; $m_{\mathrm{v}}=0.685(-) ; m_{\mathrm{h}}=0.0(-)$.

Equations (4) and (5) are a reasonable representation of $G_{\max }$ and $M_{\max }$ for air-pluviated, dry M1 sand, having a predictive error of less than $10 \%$. Field measurements suggest that different depositional environments can influence the values of the various parameters.

The degradation of shear modulus with strain was investigated with four resonant column (RC) tests and one cyclic torsional shear (CTS) test. The normalised decay of the shear stiffness $G / G_{\max }$ and the increase in damping ratio $D$ as a function of the shear strain $\gamma$ are shown in Fig. 11. The elastic threshold of M1 sand is at a shear strain value of about $\gamma=0.0005 \%$, irrespective of the void ratio and confining pressure. The trends in decay of the shear stiffness and increase of damping of M1 sand are not strongly influenced by consolidation pressure in the range of stress considered in this investigation. Instead the type of test seems to affect the measured dynamic behaviour.

The results of resonant column tests carried out on Quiou sand (Fioravante et al., 1994a) and on S1 sand (Van Impe et al., 2015) are provided in Fig. 11 for comparison. M1, S1 and Quoiu sands tested at $100 \mathrm{kPa}$ of confining pressure have very similar behaviour, both in terms of elastic threshold and variation of stiffness and damping once the elastic threshold 
Table 1. Small-strain stiffness of M1 sand and other carbonate and silica sands

\begin{tabular}{|c|c|c|c|c|c|c|c|}
\hline & $\begin{array}{c}C_{\mathrm{G}}: \\
\mathrm{MPa}\end{array}$ & $d:$ & $\begin{array}{l}n_{\mathrm{v}}: \\
-\end{array}$ & $\begin{array}{l}n_{\mathrm{h}}: \\
-\end{array}$ & $\begin{array}{c}n_{\mathrm{v}}+n_{\mathrm{h}}: \\
-\end{array}$ & $\begin{array}{l}e^{*}: \\
-\end{array}$ & $\begin{array}{c}G_{0}: \\
\mathrm{MPa}\end{array}$ \\
\hline M1 sand & $65 \cdot 3$ & -1 & $0 \cdot 378$ & $0 \cdot 306$ & $0 \cdot 684$ & $0 \cdot 745$ & $87 \cdot 65$ \\
\hline KS (Fioravante et al., 2013) & 156 & $-1 \cdot 2$ & $0 \cdot 238$ & $0 \cdot 286$ & $0 \cdot 524$ & $1 \cdot 529$ & $93 \cdot 72$ \\
\hline S1, BAE, BAW sands (Van Impe et al., 2015) & 119 & $-0 \cdot 78$ & $0 \cdot 32$ & $0 \cdot 3$ & 0.62 & $1 \cdot 13$ & $108 \cdot 13$ \\
\hline Quiou sand (Fioravante et al., 1998) $\dagger$ & 96 & $-1 \cdot 3$ & & & $0 \cdot 612$ & $1 \cdot 056$ & $89 \cdot 44$ \\
\hline Ticino sand (Fioravante, 2000) & 83 & $-0 \cdot 8$ & $0 \cdot 272$ & $0 \cdot 168$ & $0 \cdot 44$ & $0 \cdot 748$ & $104 \cdot 65$ \\
\hline
\end{tabular}

*Void ratio relating to a $50 \%$ relative density.

$\dagger$ From resonant column tests on isotropically consolidated samples.

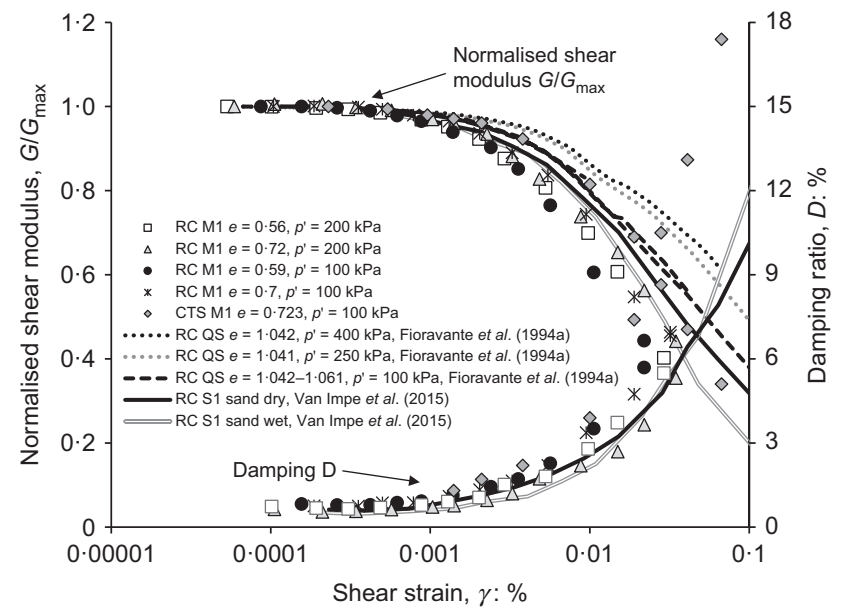

Fig. 11. Comparison of small-strain behavior of M1 sand with other carbonate sands

has been exceeded. Quoiu sand tested at higher confining pressures shows a higher elastic threshold.

\section{CONSOLIDATED STRESS RATIO $K_{0}$ IN M1 CARBONATE SAND}

$K_{0}$ consolidated triaxial compression loading was carried out to estimate the horizontal stress following dry pluviation of laboratory specimens. Results of three such tests at different void ratios are shown in Fig. 12. During these tests the radial stress was adjusted to maintain zero radial strain of the samples (measured by two proximity transducers with a sensitivity of $0 \cdot 2 \mu$ ) as the vertical stress increased. On the basis of the measurements an average value of $K_{0}=0.5$ can be taken as a reference value for laboratory samples reconstituted by way of pluvial deposition in air and then consolidated. However, the in situ $K_{0}$ in any circumstance is likely to be different, as it is well known that depositional and densification processes have a large influence on the horizontal stresses.

\section{CYCLIC BEHAVIOUR OF M1 CARBONATE SAND}

The cyclic strength for seismic or other dynamic analyses is typically measured in either cyclic triaxial tests (CTXTs) or cyclic simple shear tests (CSSTs). Both were carried out on M1 sand.

Figure 13 shows a typical CSST result, in which failure (defined as double amplitude shear strain, $\gamma_{\mathrm{DA}}=5 \%$ ) occurs in about 12 cycles of loading for the applied cyclic stress ratio of $0 \cdot 15$.

The results of 12 CSSTs are shown in Fig. 14(a), where the cyclic stress ratio (CSR) in simple shear condition

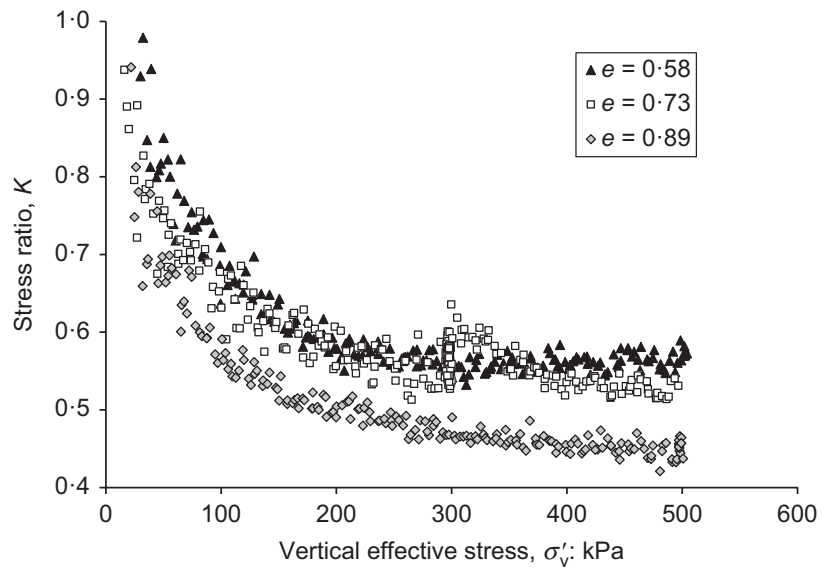

Fig. 12. Triaxial $K_{0}$ consolidation tests on specimens of M1 sand

$\mathrm{CSR}^{\mathrm{SS}}=\tau / \sigma_{\mathrm{v}}^{\prime}$ is plotted against number of cycles at a double amplitude shear strain $\gamma_{\mathrm{DA}}=5 \%$. Results of 15 CTXTs are shown in Fig. 14(b) $\left(\mathrm{CSR}^{\mathrm{TX}}=\Delta \sigma_{\mathrm{a}} / 2 \sigma_{\mathrm{c}}^{\prime}\right.$ plotted against double amplitude axial strain $\varepsilon_{\mathrm{a}, \mathrm{DA}}=2 \cdot 5 \%$ ).

Figures 14(a) and 14(b) define cyclic strength curves at the reference pressure of the test $(100 \mathrm{kPa})$ for a range of void ratios and initial state parameter values. All the specimens had negative values of $\psi_{0}$, indicating dilatant behaviour and underwent the typical response known as 'cyclic mobility' (Castro, 1975). These data (Figs 14(a) and 14(b)) were used to derive the cyclic stress to induce failure in a given number $N$ of cycles for a given value of state parameter or void ratio.

The cyclic resistance of M1 sand is comparable to or lower than that of other carbonate sands, tested at the same test conditions, as shown in Fig. 15. In Fig. 15(a) results are compared of CSSTs on M1 sand and Quiou sand (Porcino et al., 2008); in Fig. 15(b) results of CTXTs on medium-dense M1 sand are compared to analogous data reported by Hyodo et al. (1998) and Sandoval et al. (2011).

\section{ASSESSMENT OF M1 CARBONATE SAND BEHAVIOUR COMPARED WITH OTHER CARBONATE AND SILICA SANDS}

A summary of static and cyclic data from a comprehensive laboratory investigation of the M1 carbonate sand has been provided, with limited comparison with other carbonate sands (Figs 3, 6, 11 and 15). Significant differences have been noted in the mechanical properties of carbonate and silica sands, due in large part to the nature of the carbonate grains, their porosity, compressibility and high intergranular friction. This highlights the uncertainties associated with estimation of engineering properties of carbonate soils when relying on SPT- and CPT-based correlations, which 


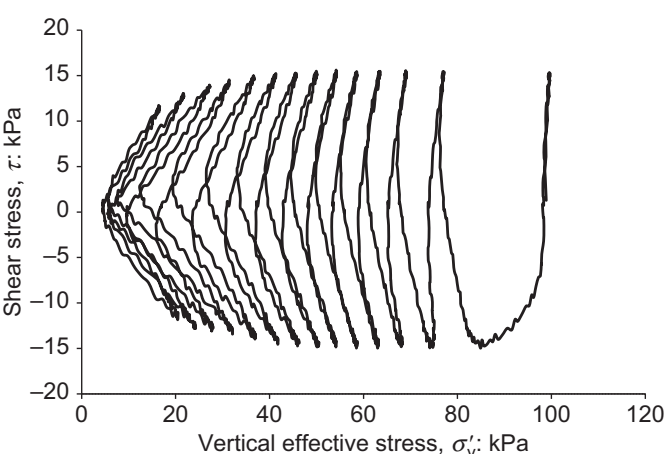

(a)

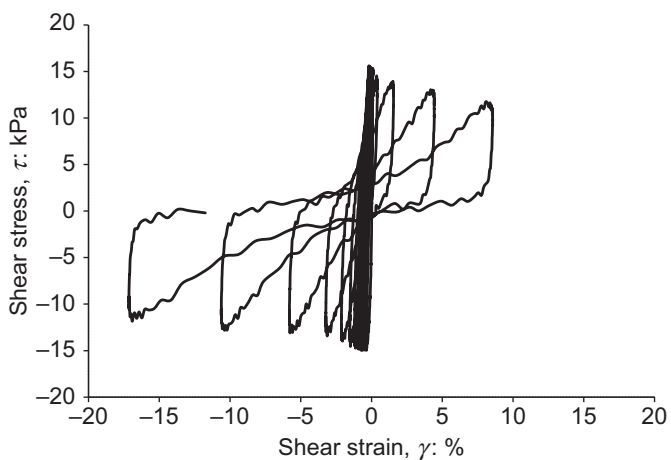

(b)

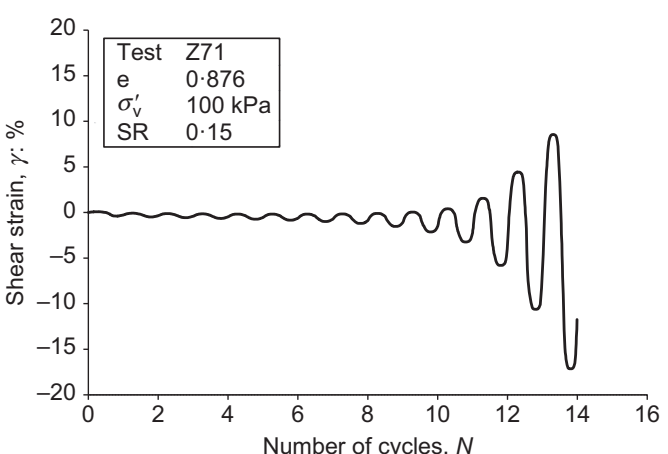

(c)

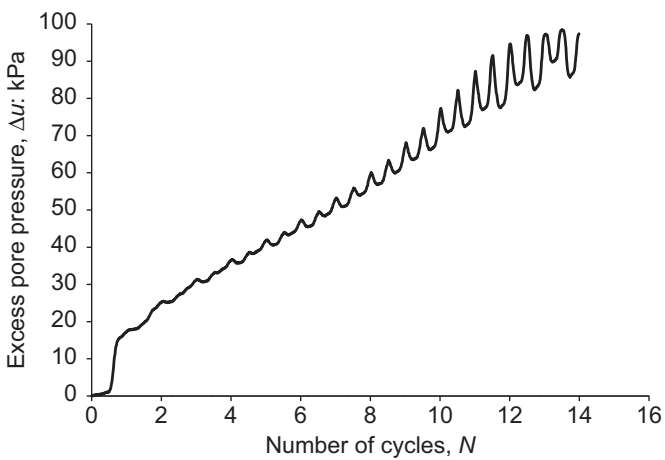

(d)

Fig. 13. Example of cyclic simple shear test (CSST) - with failure at about 12 loading cycles under a cyclic stress ratio (in simple shear) of $0 \cdot 15$ (test Z71, $e=0 \cdot 876, \sigma_{\mathrm{v}}^{\prime}=100 \mathrm{kPa}$ ): (a) effective stress path; (b) stress-strain behaviour; (c) shear strains plotted against number of cycles; (d) excess pore pressure plotted against number of cycles

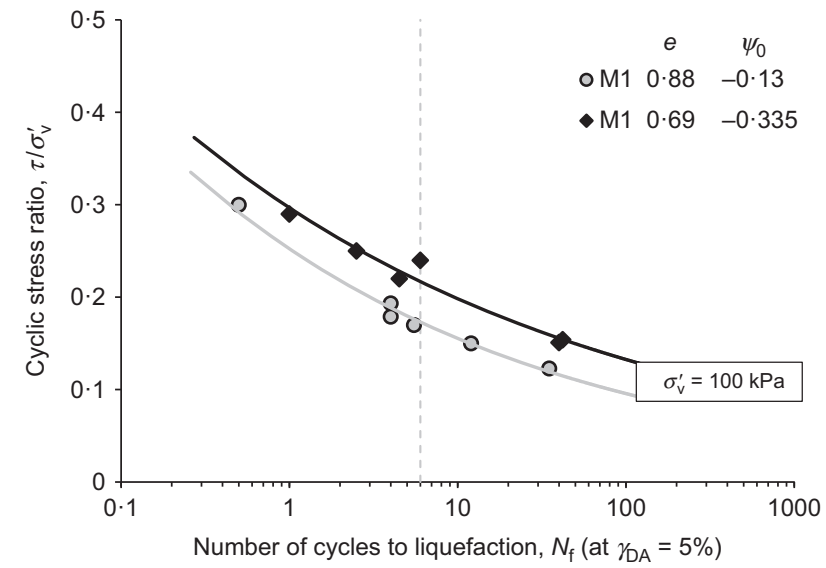

(a)

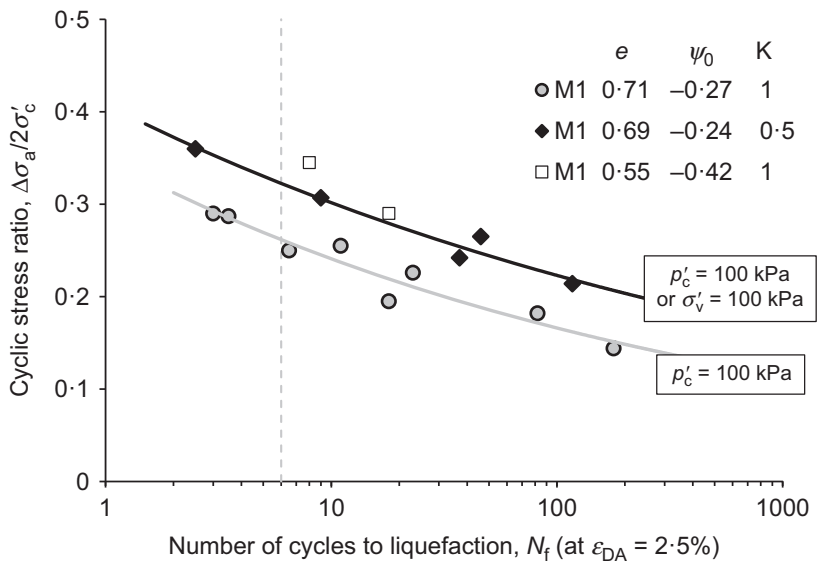

(b)

Fig. 14. Results of cyclic tests on M1 sand: (a) CSST tests; (b) CTXT tests

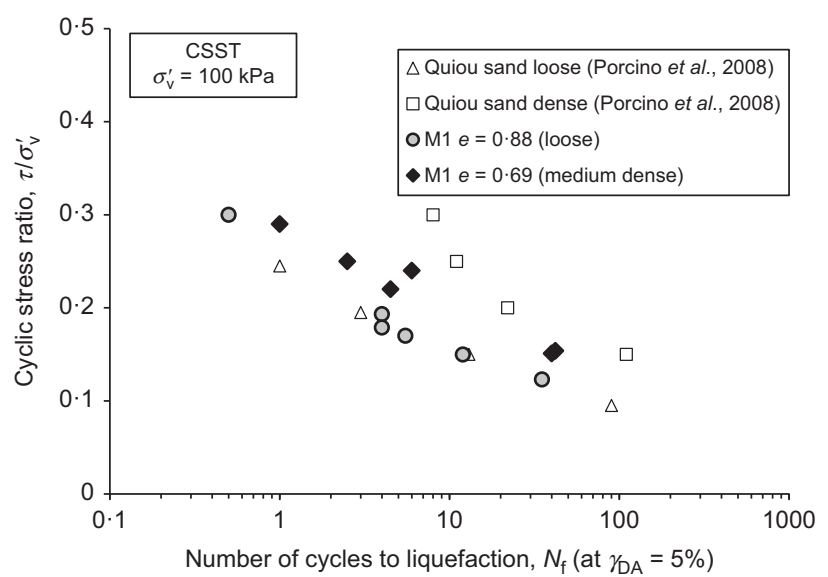

(a)

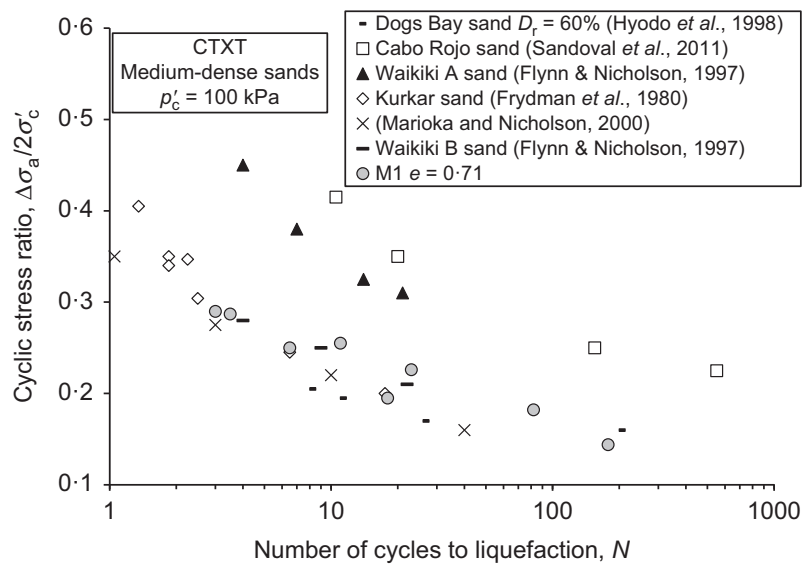

(b)

Fig. 15. Cyclic behaviour, comparison of M1 sand with other carbonate sands: (a) CSST tests; (b) CTXT tests 


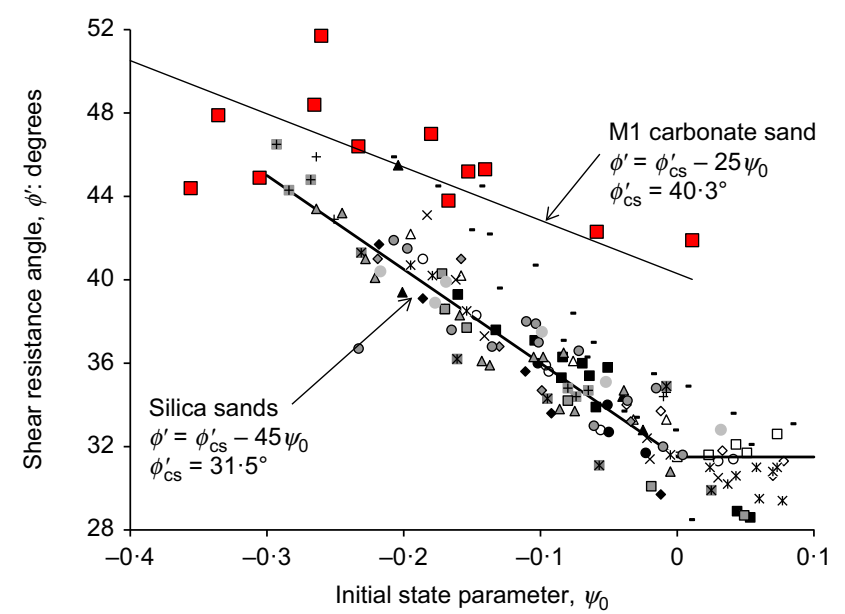

(a)

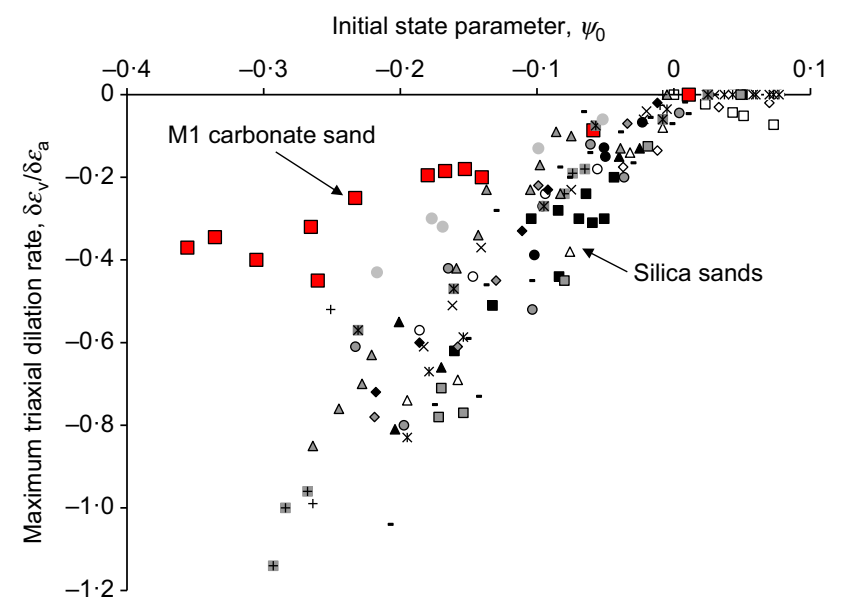

(b)

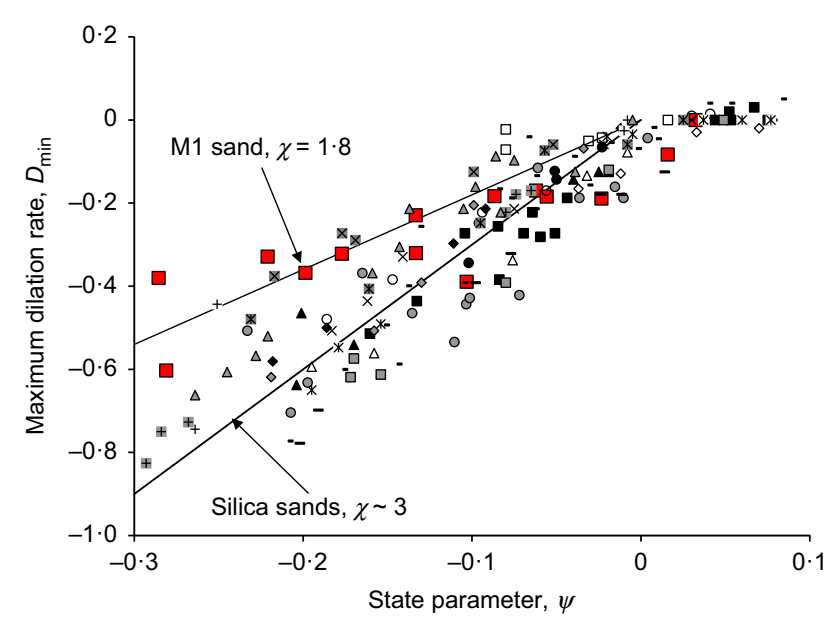

(c)

Fig. 16. Stress dilatancy data for M1 sand compared to a selection of silica sands: (a) shear resistance angle; (b) triaxial dilation rate; (c) stress invariant dilation rate scaling

are largely based on testing in silica-rich sands. Additional comparisons are made herein to assist practitioners in bracketing representative ranges of various material properties for project applications involving carbonate sands similar in composition to the M1 sand.

Figure 16(a) shows the shear resistance angle plotted against state parameter relationship of M1 sand compared to a large number of silica sands and silts. Because of the high critical state friction ratio of M1 sand, the trend line lies well above that for silica sands (at $\psi_{0}=0$, the shearing resistance angle is $40 \cdot 3^{\circ}$ ). Fig. 16(b) shows the dilation rate at the peak shear resistance angle plotted against state parameter, which demonstrates that there is somewhat less dilatancy effect at the same $\psi_{0}$ value in M1 sand. This behaviour is assumed to be a manifestation of crushing and compressibility. In Fig. $16(\mathrm{c})$ the peak dilation rate $\left(D_{\min }\right)$ plotted against state parameter is shown for silica and M1 sand. Once again, it can be seen that the carbonate sand compressibility results in a much reduced dilatancy at the same state parameter, reflected in the low $\chi$ value $(\chi=1 \cdot 8)$ compared to silica sands $(\chi=3)$ reported earlier.

The cyclic strength curve is important for liquefaction assessment, although a consistent basis for comparison of cyclic strengths of sands and silts can be difficult because of the paucity of cyclic testing that is typically carried out for projects and the number of factors that influence the cyclic strength. Fig. 17 shows the cyclic triaxial test results for a large number of silica sands and tailings with the cyclic triaxial data for M1 superimposed. M1 sand lies somewhere close to the middle of the silica sand trend; however, the range of states for the various testing programmes precludes generalisations pertaining to the relative cyclic resistance of the crushable, carbonate sand tested in this investigation and the broad range of siliceous sands summarised in Fig. 17. It should be noted that a thorough examination of the cyclic resistance of the M1 sand involving centrifuge, calibration chamber, and both laboratory and in situ CPT soundings has demonstrated that liquefaction triggering procedures developed from the worldwide database of case histories in predominantly silica-rich sands should not be applied for carbonate sands without considerable judgement and project-specific cyclic data.

\section{CONCLUSIONS}

This paper has presented a summary of laboratory data for a carbonate sand. The synthesis of this data set provides a practical example for geotechnical engineers charged with developing fill densification requirements and foundation performance specifications in carbonate sands.

Comparison of the compressibility and CSL locations with other carbonate sands indicates that M1 sand is typical in these aspects to other uncemented biogenic (shell-rich) carbonate sands.

Relating the stress-dilatancy (friction angle, dilatancy and state parameter) of M1 sand to silica sands (see Table 2) reveals significant differences that are considered to be due to the compressible nature of the carbonate soils. The high critical state or constant volume friction angle of M1 sand accounts for part of the differences. Empirical correlations developed with silica sands should not be applied to carbonate sands. The data have also been considered in terms of the dilatancy scaling parameter $\chi$, which appears to reflect a complex combination of intrinsic properties (grain size distribution, particle shape, mineralogy etc.). M1 sand appears to have a lower value of $\chi$ than the typical range seen in silica sands, but further research and data are needed to confirm if this occurs more generally and is an important aspect of carbonate sand behaviour.

There are limited data available on the cyclic strength and liquefaction resistance of carbonate sand, which complicates simple comparison to silica-rich sands. The fact that the CSL is seldom developed in the same soils for which there is cyclic simple shear testing compounds difficulties in making this comparison. With the objective of contributing a valuable, yet small, base of cyclic data for a carbonate sand, data have been presented here with state parameter as the state variable so that there is a basis for comparison with other data. 


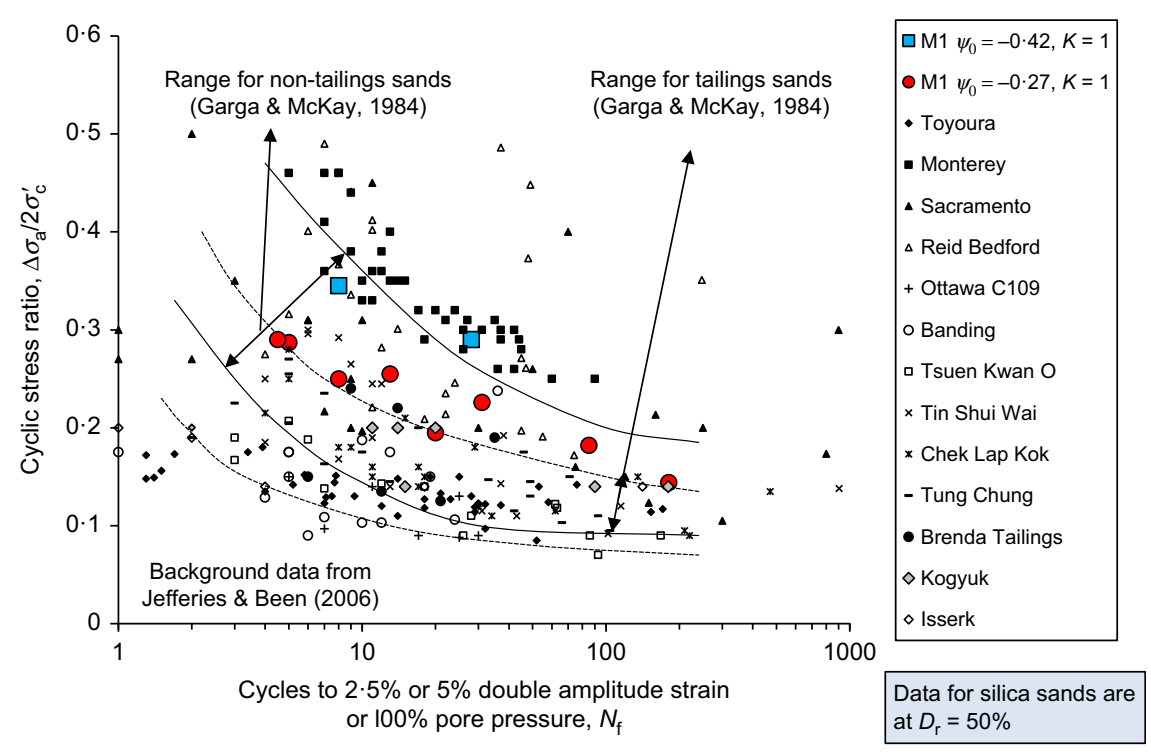

Fig. 17. Cyclic stress ratio in triaxial testing $\mathrm{CSR}^{\mathrm{TX}}$ for sands, tailings and $M 1$ sand

Table 2. Mechanical properties of M1 compared with silica sand

\begin{tabular}{|c|c|c|c|c|}
\hline Property & & $\begin{array}{l}\text { Comparison to silica } \\
\text { sands }\end{array}$ & Reasons & Figure \\
\hline Compressibility & $\begin{array}{l}\lambda_{10}=0 \cdot 296 \\
\Gamma_{1}=1 \cdot 566\end{array}$ & Higher & $\begin{array}{l}\text { Higher volume of voids, intra-particle voids, } \\
\text { particle crushing }\end{array}$ & \\
\hline $\begin{array}{l}\text { Critical state shear resistance } \\
\text { angle }\end{array}$ & $\phi_{\mathrm{cv}}=40 \cdot 3^{\circ}$ & Higher & Particle shape, angularity, mineralogy & 16(a) \\
\hline Peak shear resistance angle & & Lower & Lower dilatancy & $16(\mathrm{~b})$ \\
\hline Dilation rate & & Lower & Grain compressibility, micro and macro crushing & $16(c)$ \\
\hline Cyclic resistance & CRR & Higher & Grain compressibility, micro particle voids & 17 \\
\hline
\end{tabular}

Comparison of cyclic strength of M1 sand and silica sands at the same state parameter is inconclusive, but the evidence weakly suggests that the M1 sand is more resistant to the generation of excess pore pressure leading to liquefaction.

The test results summarised in this paper are part of a larger engineering project in which the CPT was a significant tool for confirming the in situ state of the islands constructed with sands such as M1. A companion paper (Giretti et al., 2017) examines the calibration of the CPT based on the data presented here and both centrifuge CPT tests and four large calibration chamber tests.

The authors' intention with this paper, and its companion, is to provide high-quality laboratory test data on a carbonate sand, with the hope that this may contribute to on-going research on a subset of soils in which there is a critical need for additional data.

$\begin{aligned} & \text { NOTATION } \\ & a \text { fitting parameter } \\ & b \text { fitting parameter } \\ & C_{\mathrm{G}} \text { fitting parameter } \\ & C_{\mathrm{m}} \text { fitting parameter } \\ & c \text { fitting parameter } \\ & D \text { dilation rate } \\ & D_{10} \text { diameter corresponding to } 10 \% \text { cumulative undersize } \\ & \text { particle size distribution } \\ & D_{50} \text { mean grain size diameter } \\ & D_{60} \text { diameter corresponding to } 60 \% \text { cumulative undersize } \\ & \text { particle size distribution } \\ & D_{\mathrm{r}} \text { relative density } \\ & d \text { fitting parameter } \\ & e \text { void ratio }\end{aligned}$

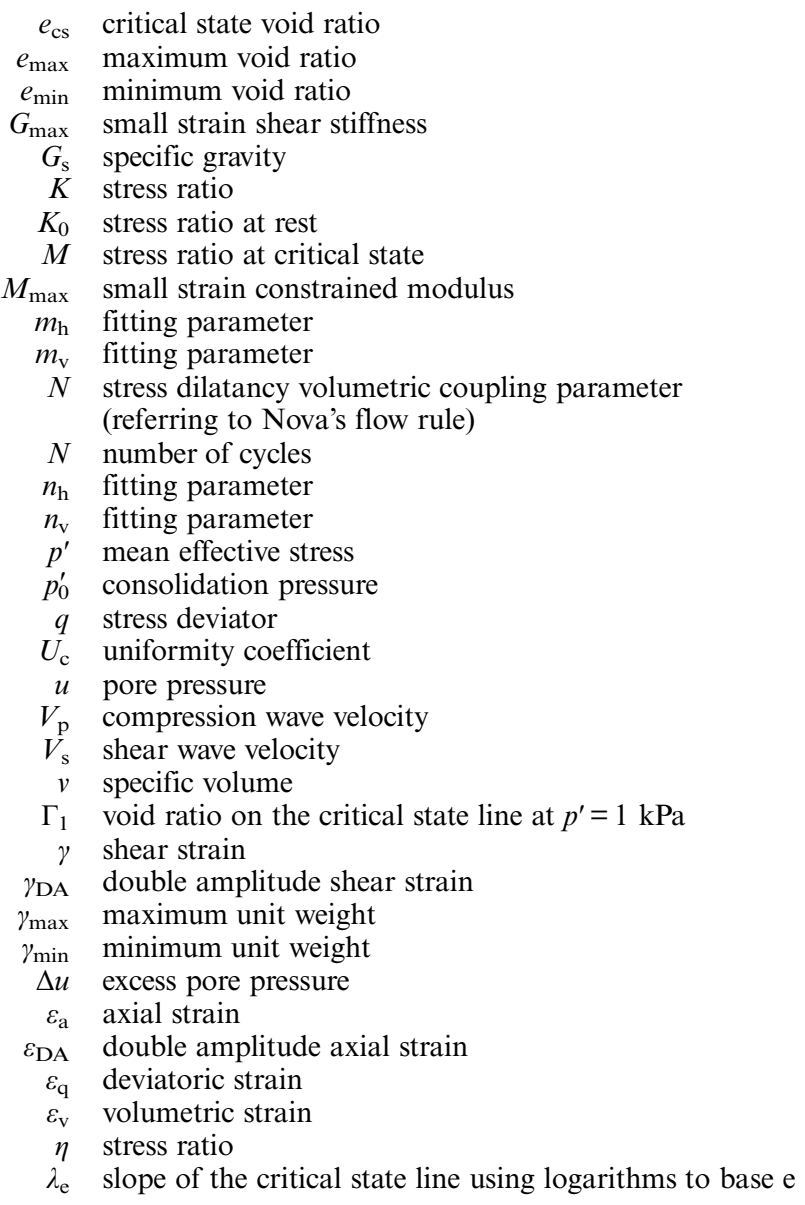


$\lambda_{10}$ slope of the critical state line using logarithms to base 10

$\rho$ soil density

$\sigma_{\mathrm{a}}$ axial stress

$\sigma_{\mathrm{c}}^{\prime}$ end of consolidation cell pressure

$\sigma_{\mathrm{h}}^{\prime} \quad$ horizontal effective stress

$\sigma_{\mathrm{v}}^{\prime} \quad$ vertical effective stress

$\tau$ shear stress

$\phi_{\mathrm{cs}}^{\prime} \quad$ shearing resistance angle at critical state

$\chi \quad$ dilatancy scaling parameter

$\psi \quad$ state parameter

$\psi_{0} \quad$ initial state parameter

\section{REFERENCES}

Al-Douri, R. H. \& Poulos, H. G. (1991). Static and cyclic direct shear tests on carbonate sands. Geotech. Testing J. 15, No. 2, 138-157.

Almeida, M. S. S., Jamiolkowski, M. \& Peterson, R. W. (1991). Preliminary results of CPT tests in calcareous Quiou sand. In Calibration chamber testing (ed. A. B. Huang), pp. 41-53. New York, NY, USA: Elsevier.

Been, K. \& Jefferies, M. G. (1985). A state parameter for sands. Géotechnique 35, No. 2, 99-112, http://dx.doi.org/10.1680/geot. 1985.35.2.99.

Boese, R. J. (1989). The study of the mechanical behaviour of uncemented carbonate sands. BSc dissertation, The City University, London, UK.

Boulanger, R. W. \& Idriss, I. M. (2014). CPT and SPT based liquefaction triggering procedures, Report No. UCD/CGM-14/01. Davis, CA, USA: Center for Geotechnical Modeling, Department of Civil and Environmental Engineering, University of California.

Brandes, H. G. (2011). Simple shear behavior of calcareous and quartz sands. Geotech. Geol. Engng 29, No. 1, 113-126.

Castro, G. (1975). Liquefaction and cyclic mobility of saturated sands. J. Geotech. Engng Div. 101, No. 46, 551-569.

Coop, M. R. (1990). The mechanics of uncemented carbonate sands. Géotechnique 40, No. 4, 607-626, http://dx.doi.org/10.1680/ geot.1990.40.4.607.

Coop, M. R. \& Airey, D. W. (2003). Carbonate sands. In Characterisation and engineering properties of natural soils (eds T. S. Tan, K. K. Phoon, D.W. Hight and S. Leroueil), pp. 1049-1086. Lisse, the Netherlands: Swets \& Zeitlinger.

Coop, M. R. \& Atkinson, J. H. (1993). The mechanics of cemented carbonate sands. Géotechnique 43, No. 1, 53-67, http://dx.doi. org/10.1680/geot.1993.43.1.53.

Coop, M. R. \& Cuccovillo, T. (1998). The influence of geological origin on the behavior of carbonate sands. In Problematic soils: proceedings of the international symposium on problematic soils, IS-Tohoku'98 (eds E. Yanagisawa, N. Moroto and T. Mitachi), pp. 607-610. Rotterdam, the Netherlands: Balkema.

Coop, M. R., Sorensen, K. K., Freitas, T. B. \& Georgoutsos, G. (2004). Particle breakage during shearing of a carbonate sand. Géotechnique 54, No. 3, 157-163, http://dx.doi.org/10.1680/ geot.2004.54.3.157.

Fioravante, V. (2000). Anisotropy of small strain stiffness of Ticino and Kenya Sands from seismic wave propagation measured in triaxial testing. Soils Found. 40, No. 4, 129-142.

Fioravante, V., Jamiolkowski, M. \& Lo Presti, D. C. F. (1994a) Stiffness of carbonate Quiou sand. Proceedings of the 13th international conference on soil mechanics and foundation engineering, New Delhi, India, pp. 163-167.

Fioravante, V., Capoferri, R., Hameury, O. \& Jiamialkowski, M. (1994b). Deformational characteristics of uncemented carbonate Quiou sand. In Proceedings of the international symposium on pre-failure deformation of geomaterials (eds S. Shibuya, T. Mitachi and S. Miura), pp. 55-61. Rotterdam, the Netherlands: Balkema.

Fioravante, V., Jamiolkowski, M., Ghionna, V. N. \& Pedroni, S. (1998). Stiffness of carbonate Quiou sand from CPT. In Geotechnical site characterisation (eds P. Roberston and P. W. Mayne), pp. 1039-1049. Rotterdam, the Netherlands: Balkema.

Fioravante, V., Giretti, D. \& Jamiolkowski, M. (2013). Small strain stiffness of carbonate Kenya Sand. Engng Geol. 161, 65-80.

Flynn, W. L. \& Nicholson, P. G. (1997). A comparative study of cyclic loading responses and effects of cementation on liquefaction potential of calcareous and silica sands. MSc thesis, University of Hawaii, Manoa, HI, USA.

Fookes, P. G. (1988). The geology of carbonate soils and rocks and their engineering characterisation and description. In Engineering of calcareous sediments (eds R. J. Jewell, D. C. Andrews and M. S. Khorshid), pp. 787-806. Rotterdam, the Netherlands: Balkema.

Frydman, S., Hendron, D., Horn, H. \& Steinbach, J. (1980). Liquefaction study of cemented sand. J. Geotech. Engng Div., ASCE 106, No. 3, 275-297.

Garga, V. K. \& McKay, L. D. (1984). Cyclic triaxial strength of mine tailings. J. Geotech. Engng Div., ASCE 110, No. 8, 1091-1105.

Giretti, D., Been, K., Fioravante, F. \& Dickenson, S. (2017). CPT calibration and analysis for a carbonate sand. Géotechnique, http://dx.doi.org/10.1680/jgeot.16.P.312.

Golightly, C. R. (1988). Engineering properties of carbonate sands. $\mathrm{PhD}$ thesis, University of Bradford, Bradford, UK.

Golightly, C. R. \& Hyde, A. F. L. (1988). Some fundamental properties of carbonate sands. In Engineering of calcareous sediments (eds R. J. Jewell, D. C. Andrews and M. S. Khorshid), pp. 69-78. Rotterdam, the Netherlands: Balkema.

Hyodo, M., Hyde, A. F. L. \& Aramaki, N. (1998). Liquefaction of crushable soils. Géotechnique 48, No. 4, 527-543, http://dx.doi. org/10.1680/geot.1998.48.4.527.

ISO (International Organization for Standardization) (2016). ISO 19901-4 Petroleum and natural gas industries - Specific requirements for offshore structures - Part 4: Geotechnical and foundation design considerations. Geneva, Switzerland: ISO.

Jefferies, M. \& Been, K. (2015). Soil liquefaction; a critical state approach, 2nd edn. Boca Raton, FL, USA: CRC Press.

LaVielle, T. H. (2008). Liquefaction susceptibility of uncemented calcareous sands from Puerto Rico by cyclic triaxial testing. MSc thesis, Virginia Polytechnic Institute and State University, Blacksburg, VA, USA.

Mao, X. \& Fahey, M. (2003). Behaviour of calcareous soils in undrained cyclic simple shear. Géotechnique 53, No. 8, 715-727, http://dx.doi.org/10.1680/geot.2003.53.8.715.

Marioka, B. T. \& Nicholson, P. G. (2000). Evaluation of the liquefaction potential of calcareous sand. Proceedings of the 10th international offshore and polar engineering conference, Seattle, WA, USA, pp. 494-500.

Nova, R. (1982). A constitutive model under monotonic and cyclic loading. In Soil mechanics - transient and cyclic loads (eds G. N. Pande and O. C. Zienkiewicz), pp. 343-373. Chichester, UK: Wiley.

Pestana, J. M. \& Whittle, A. J. (1995). Compression model for cohesionless soils. Géotechnique 45, No. 4, 611-631, http://dx.doi.org/10.1680/geot.1995.45.4.611.

Porcino, D., Caridi, G. \& Ghionna, V. N. (2008). Undrained monotonic and cyclic simple shear behaviour of carbonate sand. Géotechnique 58, No. 8, 635-644, http://dx.doi.org/ 10.1680/geot.2007.00036.

Qadimi, A. \& Coop, M. R. (2007). The undrained cyclic behaviour of a carbonate sand. Géotechnique 57, No. 9, 739-750, http://dx. doi.org/10.1680/geot.2007.57.9.739.

Robertson, P. K. (2009). Performance based earthquake design using the CPT. Keynote lecture. Proceedings of the international conference on performance-based design in earthquake geotechnical engineering, IS-Tokyo 2009, Tsukuba, Japan, pp. 3-20.

Sandoval, E. A., Pando, M. A. \& Olgun, G. C. (2011). Liquefaction susceptibility of a calcareous sand from Southwest Puerto Rico. Proceedings of the 5th international conference on earthquake geotechnical engineering, Santiago, Chile, paper no. LSOSA.

Schofield, A. \& Wroth, C. P. (1968). Critical state soil mechanics. London, UK: McGraw-Hill.

Van Impe, P. O., Van Impe, W. F., Manzotti, A. \& Mengé, P. (2015). Compaction control and related stress-strain behaviour of off-shore land reclamations with calcareous sands. Soils Found. 55, No. 6, 1474-1468.

Van't Hoff, J. \& van der Kolff, A. N. (eds) (2012). Hydraulic fill manual for dredging and reclamation works. Boca Raton, FL, USA: CRC Press/Balkema (Taylor and Francis Group).

Verdugo, R. \& Ishihara, K. (1996). The steady state of sandy soils. Soils Found. 36, No. 2, 81-91. 